\title{
A Case Report on D00RS Syndrome
}

\author{
Sherin Alexander
}

Department of Pharmacy Practice, Believers Church Medical College Hospital, Thiruvalla, Kerala, INDIA.

\begin{abstract}
DOORS syndrome is a genetic neurometabolic disorder. It is inherited as an autosomal recessive trait. It affects male and females in equal numbers. The main causes include TBC1D 24 mutations and genetic factors. Here we discuss a case of 11 year old boy diagnosed as DOORS syndrome with genetic cause. He was globally delayed in development and was frequently hospitalized due to recurrent seizure.
\end{abstract}

Key words: DOORS syndrome, Genetic disorder, Dysmorphic features, TBC1D24 mutations, Neurometabolic disorder.

\section{INTRODUCTION}

DOORS syndrome is a rare genetic disorder with classic symptoms like deafness, onychodystrophy (alteration in nail morphology), osteodystrophy (dystrophic growth of the bone), mental retardation and seizures. ${ }^{1,2}$ Ocular and dermatoglyphic abnormalities can also present. This syndrome occurs in both males and females equally and is inherited as an autosomal recessive trait. ${ }^{3}$ The main causes are genetic factors like consanguineous marriage, recurrence of DOORS syndrome in siblings and mutation of TBC1D24 gene. ${ }^{4}$

The diagnosis was based on physical examination and the typical characteristic features including finger and nail abnormalities, mental retardation. Sensorineural hearing loss can be verified with X-ray and auditory examinations. ${ }^{3}$

\section{CASE REPORT}

Our case was presented in Believers Church Medical College Hospital, Thiruvalla, multicentred tertiary care hospital. A male child of second degree consanguineous marriage, aged 11 years with dysmorphic features (large forehead, bilateral low set extremely folded pinna, upturned upper lips, hypoplastic nails in toes and fingers, flat nasal bridge, small fingers and hypertelorism abnormally increased distance between two organs or bodily parts) was brought to our hospital with complaints of breakthrough seizure in status. At the age of one, child had developed generalized tonic clonic seizure lasting for $15 \mathrm{~min}$. He was febrile $\left(100^{\circ} \mathrm{F}\right)$ and was given a dose of Diazepam. Also given syrup Paracetamol $5 \mathrm{ml}$ thrice a day, Somavert (pegrisomant) $3 \mathrm{ml}$ thrice a day and tablet Frisium (clobazam) $2.5 \mathrm{mg}$ twice a day. Karyotype study was done and was normal. X-ray showed acro osteolysis and increased bone density. His elder sibling died at 7 months of age. He had refractory seizure, severe hypoplasia of nails and global developmental delay. He was readmitted due to refractory seizure lasting for 45 minutes. WBC and platelets were normal. Electroencephalography (EEG) showed mild degree of generalized nonspecific disturbance of electrical function. Syrup Phenytoin $2 \mathrm{ml}$ twice a day, syrup Gardenal (phenobarbitone) $2.5 \mathrm{ml}$ twice a day and syrup Paracetamol were given. His seizures were controlled. After 2 months, he was again admitted with recurrent seizures associated with jerking movements of both limbs, uprolling of eyes and frothing from mouth. So the dose of Phenytoin was hiked up ( $3 \mathrm{ml}$ twice a day). He had low calcium $(6.1 \mathrm{mg} / \mathrm{dl})$ and vitamin D (3.0 ng/ml). But his parathyroid hormone (PTH) (1250.4 $\mathrm{pg} / \mathrm{ml})$ and lactate $(4.6 \mathrm{mmol} / \mathrm{l})$ levels were
DOI: 10.5530/ijopp.13.3.46

Address for correspondence: Dr. Sherin Alexander Clinical Pharmacist, Department of Pharmacy Practice, Believers Church Medical College Thiruvalla-689103, Kerala, INDIA.

Phone no: +919846055301 Email Id: sherinelsa94@gmail. com

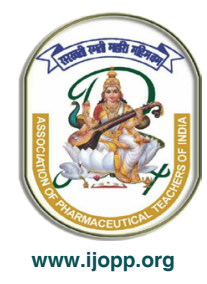


high. The abnormal laboratory values has been cited in Table 1. Phenytoin was stopped due to drug induced hypocalcaemia and levetiracetam was added. Endocrine option was taken in view of elevated PTH level and severe Vitamin D3 deficiency. He was added on calcium and Vitamin D supplementation. Now he was admitted due to 3-4 episodes of vacant stare and sleep deprivation. Developmentally he moves by bottom shuffling making cooing sound. He was treated with Midazolam and Phenytoin. His seizure frequency improved. Now he is on tablet Phenobarbitone $30 \mathrm{mg} 2-0-2 \frac{1}{2}$ (2.15mg/ $\mathrm{kg} /$ day), syrup Levetiracetam $5 \mathrm{ml}$ twice a day $(30 \mathrm{mg} /$ $\mathrm{kg} /$ day), tablet Clobazam $5 \mathrm{mg} 1-0-1 / 2(0.35 \mathrm{mg} / \mathrm{kg} /$ day) and syrup Shelcal D (Calcium Carbonate+ Vitamin $\mathrm{D}_{3}$ ) $5 \mathrm{ml}$ twice a day. Parents were counselled about the importance of taking medicines.

\section{DISCUSSION}

DOOR is a rare genetic disorder associated with four symptoms like deafness (partial or total loss of hearing due to the defect in the inner ear or auditory nerve), onychodystrophy, osteodystrophy and mental retardation. Diagnostic criteria like X-rays of both upper and lower limb, electroencephalogram (EEG) and for hearing loss, brain stem auditory evoked response should be done. Molecular genetic testing can be used for identifying a TBC1D24 mutation. ${ }^{4}$

The recurrence of DOORS in sibling and the finding of DOORS syndrome in his family with consanguinity suggest that the condition is an autosomal recessive genetic condition. EEG showed mild degree of nonspecific disturbance of electrical function and X-ray showed acro osteolysis (resorption of the distal bony phalanges). But his genetic analysis did not reveal the common TBC1D24 mutation. In this case, he had given supportive therapies like antiepileptic drugs, ${ }^{5,6}$ calcium and vitamin supplementations.

Table 1: Different lab parameters, abnormal values and normal range.

\begin{tabular}{cccc} 
Parameter & \multicolumn{2}{c}{ Reports with date } & Normal Range \\
\cline { 2 - 4 } & $\mathbf{0 4 / 1 2 / 2 0 1 9}$ & $\mathbf{0 5 / 1 2 / 2 0 1 9}$ & \\
\hline Calcium & 6.1 & 6.5 & $8.8-10.5 \mathrm{mg} / \mathrm{dl}$ \\
Vitamin D & 3 & 5 & $>30 \mathrm{ng} / \mathrm{ml}$ \\
PTH & 1250.4 & - & $15-68 \mathrm{pg} / \mathrm{ml}$ \\
Lactate & 4.6 & 3.5 & $0.5-2.2 \mathrm{mmol} / \mathrm{l}$ \\
\hline
\end{tabular}

Lal Devayanivasudevan Nair et al. ${ }^{7}$ also reported a case on DOORS syndrome. In his case report, it was a female child of non-consanguineous marriage. General examination revealed dysmorphic features like anonychia (absence of nail), low set ears, long philtrum, large lower lips and osteodystrophy. She had a history of meconium aspiration and hence developed seizures. There was no family history of any intellectual disability. Her USG, CT and MRI brain were normal. But X ray showed mild hypoplasia of the terminal phalanges of both lower and upper limbs. She was treated with antiepileptic drugs. She does not have any TBC1D24 mutation.

\section{CONCLUSION}

TBC1D24 mutation seems to be an important cause of DOORS syndrome. For this, sequencing study is required. In this syndrome, associated symptoms or disease should be treated. Seizure can be managed by antiepileptic drugs like clobazam, levetiracetam, phenytoin and phenobarbitone. And for the bone density, calcium and vitamin supplements should be given. Neurological exams like EEGs, regular hearing and ophthalmologic tests can increase the quality of life of the patient. Also speech therapy, physical therapy, genetic counselling and special remedial education will be of benefit for affected individuals and their family. Early detection or intervention is also important to ensure that children with DOORS syndrome reach their potential.

\section{ACKNOWLEDGEMENT}

The authors are thankful to the patient and his parents for their co-operation. With great pleasure I express my deep sense of gratitude to our clinical specialist, Dr. Bincy Baby, Department of Neurology for her priceless guidance and encouraging discussion during the progression of the case report.

\section{CONFLICT OF INTEREST}

The author declare no conflicts of interest.

\section{ABBREVIATIONS}

P TH: Parathyroid Hormone; EEG : Electroencephalogram; USG: Ultrasonography; CT: Computerized Tomography; MRI: Magnetic Resonance Imaging.

\section{REFERENCES}

1. Cantwell RJ. Congenital sensori-neural deafness associated with onychoosteo dystrophy and mental retardation (DOOR syndrome). Humangenetik. 1975;26(3):261-5. 
2. Girish M, Mujawar N, Salodkar A. DOOR syndrome. Indian Pediatr. 2011;48(6):479-81.

3. Wiśniewska M, Siwińska Z, Felczak M, Wielkoszyński T, Krawczyński M, LatosBieleńska A. A new case of DOOR syndrome. Journal of Applied Genetics. 2008;49(1):101-3.

4. Campeau PM, Kasperaviciute D, Lu JT, Burrage LC, Kim C, Hori M, et al. The genetic basis of DOORS syndrome: An exome-sequencing study. The Lancet Neurology. 2014;13(1):44-58
5. Alexander SNAK. A case report on anti-N-methly-D-aspartate receptor encephalitis. Asian Journal of Pharmaceutical and Clinical Research. 2017;10:3-4.

6. Sudan YS, Vinayan KP, Roy AG, Wagh A, Kannoth S, Patil S. Clinical Charecteristics and Follow-up of South Indian Children with Autoimmune Encephalopathy. The Indian Journal of Pediatrics. 2016;83(12-13):1367-73.

7. Nair LD, Sagayaraj B, Kumar R. Absence of nails, deaf-mutism, seizures and intellectual disability: A case report. Journal of Clinical and Diagnostic Research: JCDR. 2015;9(4):SD01. 